\title{
Çeşitli örneklerden izole edilen Candidaların tür dağılımı ve antifungal direnç oranları
}

\section{Distribution of Candida species isolated from various sample and antifungal resistance ratio}

\author{
Ünsal SAVCI ${ }^{*}$, Neziha YILMAZ²
}

'Hitit Üniversitesi, Çorum Eğitim Araştırma Hastanesi, Klinik Mikrobiyoloji Anabilim Dalı, Çorum, ${ }^{2}$ Bozok Üniversitesi, Tıp Fakültesi, Klinik Mikrobiyoloji Anabilim Dalı, Yozgat, TÜRKIYE

\section{ÖZ}

Amaç: Bu çalışmada Bozok Üniversitesi Araştırma ve Uygulama Hastanesi'ne başvuran hastalara ait çeşitli klinikörneklerden izole edilen Candidaların tür dağılımları ve antifungal duyarlılık oranlarının belirlenmesi amaçlanmıştır.

Gereç ve Yöntemler: Ekim 2014-Ocak 2016 tarihleri arasında Candida türleri izole edilen 42 adet klinik örnek retrospektif olarak değerlendirildi. İzolatların tanımlanmasında germ tüp testi ile ticari VITEK 2 Compact ${ }^{\circledR}$ (Biomerieux, France) maya identifikasyon sistemi kullanıldı. İzolatların antifungal duyarlılıkları flukonazol, vorikonazol, kaspofungin, mikafungin, amfoterisin B ve flusitozin antifungallerini içeren disposable VITEK 2 AST YSO2 test kartları kullanılarak belirlendi.

Bulgular: Çeşitli klinik örneklerden toplam 42 Candida türü izole edildi. C. albicans \% 66,7 ile en sık soyutlanan tür olurken, non-albicans türler \%33,3 oranında saptandı. C.albicans'ı sırasıyla C.glabrata (\%11,9), C.kefyr (\%7,1), C.tropicalis (\%4,8), C.famata $(\% 2,4)$, C.krusei $(\% 2,4)$, C.lusitaniae $(\% 2,4)$ ve C.spherica $(\% 2,4)$ izledi.

Tüm izolatların antifungal direnç oranları sırasıyla; flukonazol \%14, flusitozin \%3, vorikonazol \%6, amfoterisin-B \%5, kaspofungin \%6, mikafungin \%3 oranları belirlendi. C.albicans izolatlarında flukonazol direnç oranı \%11 olarak saptandı. C.kefyr, C.lusitaniae ve C.tropicalis izolatlarında mevcut antifungallere direnç görülmedi. C.glabrata'nın antifungal direnç oranı diğer Candida türlerine göre daha yüksekti.

Sonuçlar: Çalışmamızda en sık izole edilen C.albican'tan sonra gelen C.glabrata izolatlarının diğer Candida türlerine göre antifungal direncinin daha yüksek olduğu saptanmıştır. Son yıllarda non-albicans türlerin ve antifungal direnç oranlarının artması sebebiyle Candidaların tür düzeyinde tanımlanması ve antifungal duyarlılık testlerinin yapılmasının gerekliliği düşünülmektedir.

Anahtar Kelimeler: Candida, antifungal direnç, non-albicans

Corresponding Author*: Ünsal SAVCI, MD. Hitit Üniversitesi, Çorum Eğitim Araştırma Hastanesi, Klinik Mikrobiyoloji Anabilim Dalı, Çorum, TURKEY. Phone:00905056431925

e-mail:unsalsavci@gmail.com

Doi: $10.18663 / \mathrm{tjcl} .340562$

Received 10.06.2016 accepted 06.04.2017 


\begin{abstract}
Aim: In this study was aimed to determine the antifungal susceptibility and the distribution of Candida species isolated from different clinical samples of patients admitted to the Bozok University Research and Application Hospital.

Material and Methods: In our study, forty-two Candida species isolated from clinical samples between the October 2014 and January 2016 dates were evaluated retrospectively. For the identification of isolates; germ tube test and commercial VITEK 2 Compact $^{\oplus}$ (Biomerieux, France) was used the yeast identification system. Antifungal susceptibility of isolates was detected by using VITEK 2 AST YSO2 disposable test cards containing fluconazole, voriconazole, caspofungin, micafungin, amphotericin-B and flucytosine for use with VITEK ${ }^{\circledast} 2$ instruments.
\end{abstract}

Results: A total of 42 Candida species were isolated from various clinical specimens. C. albicans was the most frequently isolated species with $66.7 \%$ while non-albicans species were detected in $33.3 \%$. Other Candida species were as follows; C. glabrata (11.9\%), C.kefy is (7.1\%), C.tropicalis (4.8\%), C.famata (2.4\%), C.kruse (2.4\%), C.lusitania (2.4\%) and C.spherica (2.4\%), respectively.

In all isolates, the rates of antifungal resistance were found $14 \%$ for fluconazole, $6 \%$ for voriconazole, $5 \%$ for amphotericin-B, $6 \%$ for caspofungin and 3\% for micofungin. Fluconazole resistance rate was found as $11 \%$ in $\mathrm{C}$. albicans isolates. In the isolates of C.kefyr, C.lusitania and C.tropicalis was not saw resistance to existing antifungals. Antifungal resistance ratio of C. glabrata was higher than the other Candida species.

Conclusion: In our study the isolates of C. glabrata following the most frequently isolated C. albicans were found to have higher antifungal resistance than the other Candida species. In recent years, due to the increase of non-albicans species and antifungal resistance rates, it has been thought that identification of Candida species and antifungal susceptibility tests should be done.

Keywords: Candida, antifungal resistance, non-albicans

\section{Giriş}

Son yıllarda modern tedavi yöntemlerinin gelişmesi, çeşitli nedenlerle kemoterapi, immunsupresif tedavi sayısında ve transplantasyon imkanlarında artış, yoğun bakım ünitesinde yatan hasta sayısının artması, parenteral beslenme, geniş spektrumlu yada kombine antibiyotik kullanımında artış, tanı veya tedavi amaçlı invazif işlemlerin uygulanması Candida enfeksiyonlarının sıklığında artışa yol açmıştır [1-3]. Bu hastalar risk grubu olarak değerlendirilir ve bu hasta grubunda gelişen fırsatçı mantar enfeksiyonlarının çoğunluğunda Candida türlerine ait patojenler izole edilmektedir [1,4].

Kandidemi ve kandidüri dışında invazif Candida enfeksiyonlarında tanı koymak oldukça zordur. Bu nedenle hasta yönetim ve tedavisinde kandidiyazis risk faktörleri göz önünde bulundurulmalıdır [5]. Candida türleri nozokomiyal kan dolaşımı enfeksiyonlarına neden olan patojenler arasında dördüncü sırada yer almaktadır [6,7]. Hastane mantar enfeksiyonlarının büyük bir kısmından (\%80) Candida türleri sorumludur. Nozokomiyal enfeksiyonlara en sık neden olan Candida türü Candida albicans'tır [7-9]. Son 15 yıldır nonalbicans Candida türlerinin neden olduğu enfeksiyonların sıklığı hızla artmıştır. Çeşitli araştırmalarda fungemi ataklarının yarıdan fazlasında non-albicans Candidaların sorumlu olduğu görülmüştür. Azollerin yaygın kullanımı epidemiyolojinin değişmesinde en önemli faktör olarak öne sürülmüştür [10].

Mantar enfeksiyonlarının sıklığının artışı, mortalite ve morbiditede oranlarında artışa neden olmakta ve antifungallerin ampirik kullanımını yaygınlaştırmaktadır. Antifungallerin ampirik tedavide daha yaygın kullanılması, dirençli mantar izolatların oluşumunu kolaylaştırmakta ve dirençli izolat oranlarında artışa sebep olmaktadır. Antifungallere direnç gelişimini azaltmak, etkili antifungal tedavi uygulamak için in vitro olarak duyarlılık testlerinin yapılması gerekmektedir [11].

Bu çalışmada, hastanemizde 16 aylık süre içerisinde çeşitli örneklerden izole edilen Candida türlerinin fenotipik identifikasyonu ve antifungal duyarlılık profilinin ortaya konulması amaçlanmıştır.

\section{Gereç ve Yöntemler}

Ekim 2014-Ocak 2016 tarihleri arasında mikrobiyoloji laboratuarına gelen 14 vajen sürüntüsü, 13 idrar, 7 bronkoalveolar lavaj, 7 balgam ve 1 yara olmak üzere toplam 42 klinik örnekte izole edilen Candida türleri retrosektif olarak değerlendirildi. Çalışma Helsinki Deklarasyonuna uyumlu 
şekilde yürütülmüştür. Koyun kanlı agar besiyerinde üreyen kolonilerin gram boyamasında maya hücreleri görülen örnekler, 2 adet sabouraud dekstroz agar besiyerine pasaj alınarak, besiyerlerinden birisi $37^{\circ} \mathrm{C}$, diğeri $25^{\circ} \mathrm{C}$ de 24 saat inkübe edildi. İolatların tanımlanmasında germ tüp testi ile ticari VITEK 2 Compact $^{\oplus}$ (Biomerieux, France) maya tanımlama sistemi kullanıldı. İzolatların antifungallere karşı duyarlılıkları flukonazol, vorikonazol, kaspofungin, mikafungin, amfoterisin-B ve flusitozin antifungallerini içeren disposable VITEK 2 ASTYSO2 test kartları kullanılarak belirlendi. Bahsedilen antifungal duyarlıık testleri Clinical and Laboratory Standards Institute (CLSI) tavsiyeleri gözönüne alınarak yapıldı.

Kullanılan antifungaller için MIC değerleri; amfoterisin-B için $\leq 0,25 \mu \mathrm{g} / \mathrm{mL}$, kaspofungin için $\leq 0,25 \mu \mathrm{g} / \mathrm{mL}$, flukonazol için $\leq$ $1 \mu \mathrm{g} / \mathrm{mL}$, flusitozin için $\leq 1 \mu \mathrm{g} / \mathrm{mL}$, mikafungin için $\leq 0,06 \mu \mathrm{g} /$ $\mathrm{mL}$ ve vorikonazol için $\leq 0,12 \mu \mathrm{g} / \mathrm{mL}$ dir. Gruplar arası sayıların dağılımının karşılaştııımasında Ki-Kare Testi kullanıldı. Sonuçlar sayı ve yüzde $(n, \%)$ olarak verildi.

\section{Bulgular}

Hastaların \%50'si (21) erkek, \%50'si (21) kadındı. Hastaların yaşları 2 ile 92 arasında değişiyordu. 42 izolatın 16 tanesi (\%38) kadın doğum polikliniği, 8 tanesi (\%19) yoğun bakım servisi, 15 tanesi (\%36) dahili birimler (iç hastalıkları, enfeksiyon hastalıkları, göğüs hastalıkları, nöroloji, pediatri ve gastroenteroloji servisleri) ve 3 tanesi (\%7) cerrahi birimlerde (üroloji ve göğüs cerrahi servisleri) tedavi gören hastalardan izole edildi.

C.albicans \%66,7 oranıyla en sık, C.glabrata \%11,9 oranıyla ikinci sıklıkta izole edilen Candida türleriydi (Tablo 1).

\begin{tabular}{|c|c|}
\hline Candida türü & Sayı(\%) \\
\hline C.albicans & $28(66,7)$ \\
\hline C.glabrata & $5(11,9)$ \\
\hline C.kefyr & $3(7,1)$ \\
\hline C.tropicalis & $2(4,8)$ \\
\hline C.krusei & $1(2,4)$ \\
\hline C.lusitaniae & $1(2,4)$ \\
\hline C.spherica & $1(2,4)$ \\
\hline C.famata & $1(2,4)$ \\
\hline Toplam & $42(100)$ \\
\hline
\end{tabular}

C.albicans bütün yaş gruplarında en sık görülen Candida türüydü. Diğer Candida türlerine 20 yaş ve altında rastlanmadı. Yirmi yaş ve altında izole edilen tek türün C.albicans olduğu görüldü. Bununla birlikte Ki-Kare testiileyapılan karşılaştırmada türlerin yaş gruplarına göre dağılımında anlamlı bir farklılık bulunamadı ( $\mathrm{X} 2=5.4, \mathrm{p}=0.979$ ) (Tablo 2 ).

$\begin{aligned} & \text { Tablo 2. Izole edilen Candida türlerinin yaş gruplarına } \\
& \text { göre dağıımı }\end{aligned}$
\begin{tabular}{lccc} 
Türler & $\leq 20$ Yaş & $21-60$ Yaş & $\geq 61$ Yaş \\
C.albicans & $\mathrm{n}(\%)$ & $\mathrm{n}(\%)$ & $\mathrm{n}(\%)$ \\
\hline C.glabrata & $0(7,1)$ & $13(46,4)$ & $13(46,4)$ \\
C.kefyr & $0(0,0)$ & $3(60,0)$ & $2(40,0)$ \\
\hline C.tropicalis & $0(0,0)$ & $1(66,7)$ & $1(33,3)$ \\
C.krusei & $0(0,0)$ & $1(100,0)$ & $1(50,0)$ \\
C.lusitaniae & $0(0,0)$ & $0(0,0)$ & $0(0,0)$ \\
C.spherica & $0(0,0)$ & $1(100,0)$ & $0(0,0)$ \\
C.famata & $0(0,0)$ & $1(100,0)$ & $0(0,0)$ \\
\hline Toplam & $2(4,8)$ & $22(52,4)$ & $18(42,9)$ \\
\hline
\end{tabular}

Tüm izolatlarda flukonazol direnç oranı \%14, C.albicans izolatlarında \%11 olarak saptandı. Mikafungine tüm izolatlar duyarlıydı.C.albicansizolatıdışındaki tümizolatlarkaspofungin ve amfoterisin-B ye duyarlı olarak saptandı. C.glabrata dışında flusitozin direnci görülmedi. C.kefyr, C.lusitaniae ve C.tropicalis izolatları tüm antifungallere duyarlıydı. C.glabrata ise diğer türlere göre daha dirençliydi. C.famata ve C.spherica'nın duyarılık testleri çalışılamadı. C.krusei izolatları intrinsik dirençli olduğu flukonazol dışındaki diğer antifungallere duyarlı olarak saptandı (Tablo 3). Candida izolatlarının klinik örneklere göre dağııımı Tablo 4'de gösterilmiştir.

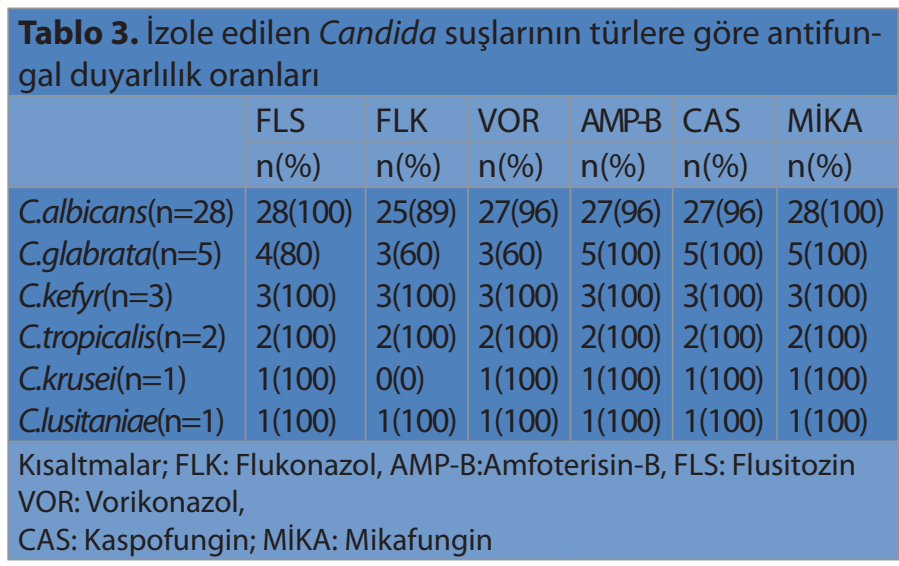

\begin{tabular}{|c|c|c|c|c|c|}
\hline Candida türü & BAL & Balgam & İdrar & Vajen & Yara \\
\hline C.albicans & 5 & 5 & 9 & 8 & 1 \\
\hline C.glabrata & 1 & 0 & 1 & 3 & 0 \\
\hline C.kefyr & 0 & 1 & 0 & 2 & 0 \\
\hline C.tropicalis & 1 & 0 & 1 & 0 & 0 \\
\hline C.krusei & 0 & 1 & 0 & 0 & 0 \\
\hline C.Iusitaniae & 0 & 0 & 1 & 0 & 0 \\
\hline C.spherica & 0 & 0 & 0 & 1 & 0 \\
\hline C.famata & 0 & 0 & 1 & 0 & 0 \\
\hline Toplam n(\%) & $7(16,7)$ & $7(16,7)$ & $13(30,1)$ & $14(33,3)$ & $1(2,4)$ \\
\hline
\end{tabular}




\section{Tartışma}

Zamanımızda tıp biliminde gelişmelerin sonucu, fungal enfeksiyonların etkilediği risk grupları genişlemektedir. Candida türleri nozokomiyal mantar enfeksiyonlarının \%80'den daha fazlasından sorumlu olmakla birlikte, nozokomiyal kan dolaşımı enfeksiyon etkenleri arasında ilk sıralarda yer almaktadır. Son zamanlarda, albicans dışı Candida izolatlarının neden olduğu enfeksiyonların giderek arttığı görülmektedir. En sık saptanan tür olan C.albicans dahil olmak üzere C.parapsilosis, C.tropicalis, C.glabrata ve C.krusei türleri, insanlarda hastalık etkeni olan 17 Candida türünün \%95'ini kapsamaktadır [12].

Günümüzde hospitalize vakalara eşlik eden akciğer ve renal hastalıklar, malignensiler gibi durumların görülme sıklığının artması, yaşam süresinde artış gibi etkenler ile hospitalize vakalarda Candida enfeksiyon sıklığı gün geçtikçe artmaktadır. Günümüzde antifungal ilaçlarile tedavi süreci erken başlamasına karşın, Candida enfeksiyonlarının mortalite ve morbidite seviyesi oldukça yüksek seyretmektedir [13]. Araştırmamızda Candida türleri geniş yaş grubu aralığında (2-92 yaş) izole edildi. Yaş artışı ile doğru orantılı olarak malignensi ve kronik hastalık prevelansının artması, aynı zamanda yaşı bireylerde immün sistemde zayıflama gibi etkenler gözününe alındığında, bilhassa hospitalize olgularda Candida enfeksiyonlarının takip ve tedavilerinde daha dikkatli olunması gerekmektedir.

Ispanya'da yedi yıl boyunca yoğun bakım ünitelerinde invaziv Candida enfeksiyonları takip edilen bir çalışmada, kandidemi gelişen hastalarda antifungal tedavi başlanmasına rağmen mortalite oranı \%39 olarak bildirildi. [14]. Hastanemiz yoğun bakım ünitesinde Candida izole edilen sekiz hastadan beşi ex oldu (Mortalite oranı \%63). Ex olan hastaların yaşları 60 ile 88 arasında değişmekteydi.

Ülkemizde Candida türlerinin dağılımları ile ilgili yapılan çalışmalarda çoğunlukla C. albicans ilk sırada yer almaktadır. Sav ve ark. [15] 1122 Candida izolatından; C. albicans $848(\% 75,6)$, C. glabrata 143 (\%12,8), C.parapsilosis 40 (\%3,57), C. krusei 33 $(\% 2,94)$, C. kefyr $33(\% 2,94)$ ve C. Tropicalis $19(\% 1,7)$; Temiz ve ark. [16] 69 Candida izolatından; C. albicans $49(\% 71,0)$, C. tropicalis $6(\% 8,7)$, C. glabrata $6(\% 8,7)$, C. Parapisilosis $5(\% 7,3)$, C. dubliniensis $2(\% 2,9)$, C. guilliermondii $1(\% 1,4)$ oranlarında bildirmişlerdir. Diğer çalışmalarda da [17-19] C. albicans çoğunlukla en sık izole edilen Candida türü olarak bildirildi.

Son zamanlarda yapılan çalışmalarda non-albicans türlerinde artış bildirildi. Etiz ve ark. [12] izole ettikleri 280 Candida suşundan en sık C.parapsilosis (\%33,9), Şahiner ve ark. [21] tarafından kan kültürlerinden izole edilen Candida türleri sırasıyla; C.parapsilosis (\%38,5), C.tropicalis $(\% 30,8)$, C.albicans $(\% 26,9)$ olarak bildirilmiştir.
Değişik ülkelerde yapılan çalışmalarda da C. albicans çoğunlukla en sık izole edilen tür olmuştur. Bailly ve ark [22] 2403 Candida suşundan sırasıyla; C. albicans \%53, C. glabrata $\% 16$, C.parapsilosis $\% 8$, C.tropicalis $\% 8$ oranlarında ve C.parapsilosis izolasyon oranının 2004 yılında \%5,7'den 2013 yılında \%8,4'e yükseldiğini bildirmişlerdir. İspanya'da 1357 Candida enfeksiyonlu hastanın değerlendirildiği bir çalışmada en sık izole edilen C. albicans'ı, C. parapsilosis takip etmiştir [23]. Phaller ve ark. [24] en sık C. albicans, ardından C. glabrata, Jung ve ark. [25] C.albicans \%38, C.parapsilosis \%26 ve C.tropicalis \%20 oranlarında tür dağılımları bildirmişlerdir. Bizim çalışmamızda çeşitli klinik örneklerden izole edilen 42 Candida suşunda C. albicans \%66,7 oranında en sık soyutlanan tür olurken, non-albicans türler $\% 33,3$ oranında izole edilmiştir. C.albicans'ı sırasıyla C.glabrata $(\% 11,9)$, C.kefyr $(\% 7,1)$, C.tropicalis $(\% 4,8)$, C.famata $(\% 2,4)$, C.krusei $(\% 2,4)$, C.lusitaniae $(\% 2,4)$ ve C.spherica $(\% 2,4)$ izlemiştir.

Candida türlerindeki dağılım coğrafi bölge farklılıkları ile birlikte hasta gruplarına göre değişiklikler göstermektedir [26]. Günümüzde Candida enfeksiyonları ile karşılaşma sıklığının artması, özellikle yoğun bakım ünitelerinde profilaktik antifungal kullanımını artırmakta, bunun sonucunda antifungallere duyarlılığı azalmış veya dirençli suşların oluşmasına sebep olmaktadır [27].

Etkin bir triazol olan flukonazol, maliyetinin de düşük olması gibi nedenler sonucu, maya kaynaklı enfeksiyonların tedavisinde en sık kullanılan antifungallerdendir. C. krusei flukonazole karşı doğal dirençlidir ve flukonazolün C. glabrata'ya karşı etkisi oldukça sınırlıdır [28]. Candida suşlarında flukonazol direncini Çekin ve ark. [29] \%4,5, Temiz ve ark. [16] C.albicans için \%4, C.glabrata için \%5 ve C.tropicalis için \%5 olarak bildirmişlerdir. Ülkemizde flukonazol direnci \% 0-38 arasında değişmekte olup, direnç giderek artmakta ve bölgelere göre değişmektedir [16]. Hastanın öyküsünde flukonazol tedavisi almış olması kandidemi gelişme olasılığını artırmaktadır [30]. Çalışmamızda tüm izolatlarda flukonazol direnç oranı \%14, C.albicans izolatlarında flukonazol direnç oranı \%11 olarak saptanmıştır. En yüksek flukonazol direncine sahip Candida türü C.glabrata olmuştur (\%40).

Amfoterisin-Ben eskipoliyengrubu ilaçlardan olan, invaziffungal enfeksiyon tedavilerinde kullanılan onaylanmış antifungal bir ilaçtır [31]. Farklı merkezlerde yapılan çalışmalarda amfoterisinB'ye karşı direnç gelişiminin oldukça düşük olduğu bildirilmiştir [12,16,17,32-34]. Çalışmamızda sadece bir C.albicans izolatında amfoterisin-B direnci saptanmıştır. 
Vorikonazol flukonazolden türetilen triazol grubu, sentetik, geniş spekturumlu yeni bir antifungal ilaçtır. Flukonazolün etkisinin sınırlı olduğu C. krusei ve $C$. glabra türleri başta olmak üzere diğer Candida türlerine de etkilidir [16]. Erdem ve ark. [18] ile Çalışkan ve ark. [27] yaptıkları çalışmalarda Candida türlerinde vorikonazol direnci saptanmazken, Özbek ve ark. [35] \% 3,63, Hancı ve ark. [36] \%22,5 oranında direnç bildirmişlerdir. Çalışmamızda bir C.albicans, iki C.glabrata izolatında vorikonazol direnci saptanmıştır.

Günümüzde çeşitli mikozların tedavisinde onay alan anidulafungin, kaspofungin ve mikafungin ekinokandin türevleridir. Flukonazole dirençli Candida türlerine karşı ekinokandinlerin etkinliği mükemmeldir. Candidanın klinik izolatları arasında ekinokandin direnci oldukça nadirdir [37]. Pfaller ve ark. [38] çok merkezli çalışmalarında kan örneklerinden izole edilen C.krusei izolatlarında \%12,5, Etiz ve ark. [12] Candida suşlarında kaspofungine \%11 oranında direnç bildirmişlerdir. Özkaya ve ark. [32] ise 93 adet Candida suşunda kaspofungin direncine rastlamamışlardır. Çalışmamızda tüm Candida izolatları mikafungine duyarlı iken, kaspofungin direnci bir C.albicans izolatında görülmüştür.

Flusitozin toksisitesi yüksek bir antifungal olmasından dolayı kullanımı oldukça sınırlıdır. Çalışkan ve ark. [27] ile Pelit ve ark [17] flusitozin direncine rastlamamışlardır. Bayram ve ark. [19] \%4, Erdem ve ark. [18] \%1,7 oranında flusitozin direnci bildirmişlerdir. Uluslararası SENTRY Antimikrobiyal Sürveyans Programı kapsamında kan kültüründen izole edilen 1201 adet Candida izolatının flusitozin direnç oranı \%4,5 olarak bildirilmiştir [39]. Çalışmamızda bir C.glabrata izolatı dışında tüm Candida türleri flusitozine duyarlıdır. Hastanemizde flusitozin direncinin düşük olması, flusitozinin tedavide sınırlı oranda kullanılmasından kaynaklanabilir.

Sonuç olarak çalışmamızda, identifiye ettiğimiz Candida türlerinde çeşitliliğin arttığı ve özellikle C.glabrata izolatlarının diğer Candida türlerine göre antifungal direncinin daha yüksek olduğu görülmüştür. Son yıllarda non-albicans türlerin ve antifungal direnç oranlarının da artması göz önüne alınarak Candidaların tür düzeyinde tanımlanması ve antifungal duyarlılık testlerinin yapılması, hem hastanemiz hem de ülke genelinde Candida enfeksiyonlarının tedavi protokollerine katkı sağlayacağı düşüncesindeyiz.

\section{Maddi Destek ve Çıkar illişkisi}

Çalışmayı maddi olarak destekleyen kişi/kuruluş yoktur ve yazarların çıkara dayalı bir ilişkisi yoktur.

\section{Kaynaklar}

1. Fridkin SK, Jarvis WR. Epidemiology of nosocomial fungal infections. Clin Microbiol Rev 1996; 9: 499-511.

2. Lass-Flörl C. The chancing face of epidemiology of invasive fungal disease in Europe. Mycoses 2009; 52: 197-205.

3. Atalay MA, Sav H, Demir G, Koç AN. Kan kültürlerinden izole edilen Candida türlerinin dağılımı ve amfoterisin b ve flukonazole in vitro duyarlılıkları. Selçuk Tıp Dergisi 2012; 28:149-151.

4. Dixon DM, Rhodes JC, Fromtling RA. Taxonomy, classification and morfology of the fungi, In "Manual of Clinical Microbiology", Ed. Murray PR, Baron EJ, Pfaller MA, Tenover FC, Yolken RH, 8rd edn. Washington DC: ASM Press, 2003: 1653- 9.

5. Eggimann $P$, Pittet D. Candida colonization index in the management of critically III patients. In: Vincent JL. (eds) Intensive Care Medicine. Springer, New York, NY 2006; 604-612.

6. Morgan J, Meltzer MI, Plikaytis BD, Sofair AN, et al. Excess Mortality, Hospital Stay, and cost due to Candidemia: A case-control study Using Data From Population-based Candidemia Surveillance. Infection Control and Hospital Epidemiology 2005;26: 540-547.

7. Pfaller MA, Diekema DJ. Epidemiology of invasive Candidiasis: a persistent public health problem. Clinical Microbiology Reviews. 2007; 20: 133-163.

8. Lunel FM, Meis JF, Voss A. Nosocomial fungal infections: Candidemia. Diagn Microbiol Infect Dis 1999; 34:213-220.

9. Wisplinghoff $H$, Bischoff T, Tallent SM, Seifert H, Wenzel RP, Edmond MB. Nosocomial bloodstream infections in US hospitals: analysis of 24,179 cases from a prospective nationwide surveillance study. Clin Infect Dis 2004; 39: 309-17.

10. Bedini A, Venturelli C, Mussini C, et al. Epidemiology of candidaemia and antifungal susceptibility patterns in an Italian tertiary-care hospital. Clin Microbiol Infect 2006; 12: 75-80.

11. Espinel-Ingroff $A$, White $T$, Pfaller MA. Antifungal agents and susceptibility test methods, pp: 1859-80. In:Murray PR, Baron EJ, Tenover FC, Yolken RH (eds), Manual of Clinical Microbiology. 2003, 8th ed. ASM Press, Washington, DC.

12. EtizP,KibarF,EkenoğluYveark. Kan kültürlerinden izoleedilen Candida türlerinin dağılımının ve antifungal duyarlııklarının retrospektif olarak değerlendirilmesi. ANKEM Dergisi 2015;29:105-113.

13. Chen PY, Chuang YC, Wang JT, et al. Comparison of epidemiology and treatment outcome of patients with Candidemia at a teaching hospital in Northern Taiwan, in 2002 and 2010. J Microbiol Immunol Infect. 2014; 47:95-103.

14. Ibanez-Nolla J, Nolla-Salas M, Leon MA, et al. Earlydiagnosis of Candidiasis in non-neutropenic critically ill patients. J Infect 2004; 48: 181-192. 
15. Sav H, Demir G, Atalay MA ve ark. Klinik örneklerden izole edilen Candida türlerinin değerlendirilmesi. Türk Hij Den Biyol Derg: 2013; 70: 175-80.

16. Temiz H, Temiz S ve Kaya Ş. Çeşitli klinik örneklerden izole edilen Kandida türlerinin dağılımı ve antifungal duyarlılıkları. Okmeydanı Tıp Dergisi 2015; 31:13-17.

17. Pelit S, Uzun M. Yoğun bakım ünitelerinde yatan hastalara ait çeşitli klinik örneklerden izole edilen candida suşlarında tür dağııımının ve antifungal duyarlılıkların araştırılması. Yoğun Bakım Derg 2016; 7: 49-52.

18. Erdem F, Tuncer Erdem G, Oral B, Karakoç E, Demiröz AP, Tülek N. Candida türlerine bağlı nozokomiyal enfeksiyonların epidemiyolojik ve mikrobiyolojik açıdan değerlendirilmesi. Mikrobiyol Bul 2012; 46: 637-48.

19. Bayram Y, Gültepe B, Güdücüoğlu H. Çeşitli klinik örneklerden izole edilen Candida kökenlerinin identifikasyonu ve antifungal duyarlılıklarının araştırılması. Van Tıp Derg 2012; 19: 177-81.

20. Satılmış ÖK, Akkaya Y, Ergin Ç, Kaleli İ. Çeşitli klinik örneklerden izole edilen Candida sp kökenlerinde slime faktör üretimi. Pam Tip Derg 2011; 4: 25-9.

21. Şahiner F, Ergünay $K$, Özyurt M, Ardıç N, Hoşbul T, Haznedaroğlu T. Hastane enfeksiyonu etkeni olarak izole edilen Candida suşlarının genotipik ve fenotipik olarak tanımlanması, Mikrobiyol Bul 2011;45:478-88.

22. Bailly $S$, Maubon D, Fournier $P$, et all. Impact of antifungal prescription on relative distribution and susceptibility of Candida spp. - Trends over 10 years. Journal of Infection 2016; 72: 103-111.

23. Pemán J, Cantón E, Quindós G, Eraso E, Alcoba J, Guinea J et al. Epidemiology, species distribution and in vitro antifungal susceptibility of fungaemia in a Spanish multicentre prospective survey. J Antimicrob Chemother 2012; 67: 1181-7.

24. Phaller MA, Boyken LB, Hollis RJ, Kroeger J,Messer SA, Tendolkar S et al. Validation of 24-hour posaconazole and voriconazole MIC readings versus the CLSI 48-hour broth microdilution reference method: application of epidemiological cut off values to results from a global Candida antifungal surveillance program. J Clin Microbiol 2011; 49: 1274-9.

25. Jung $\mathrm{SI}$, Shin $\mathrm{JH}$, Song $\mathrm{JH}$ et al and Korean Study Group for Candidemia. Multicenter surveillance of species distribution and antifungal susceptibili-ties of Candida bloodstream isolates in South Korea. Med Mycol 2010; 48:669-74.

26. Warnock DW. Trends in the epidemiology of invasive fungal infections. Nihon Ishinkin Gakkai Zasshi 2007; 48: 1-12.

27. Çalışkan E, Dede A, Biten Güven G. Kan kültürlerinde saptanan Candida türlerinin dağılımı ve antifungal duyarlılıkları. ANKEM Derg 2013; 27: 25-30.
28. Wang $\mathrm{H}$, Xiao $\mathrm{M}$, Chen $\mathrm{SC}$, Kong $\mathrm{F}$, Sun $\mathrm{ZY}$, Liao $\mathrm{K}$, et al. In vitro susceptibilities of yeast species to fluconazole and voriconazole as determined by the 2010 National China Hospital Invasive Fungal Surveillance Net (CHIF-NET) study. J Clin Microbiol 2012; 50: 3952-9.

29. Çekin $Y$, Pekintürk $N$, Cekin AH. Evaluation of species distribution and antifungal resistance of Candida isolates from hospitalized patients. J Clin Anal Med 2015; 6: 8-11.

30. Garnacho-Montero J, Diaz-Martin A, Garcia-Cabrera E, et al. Risk factors for fluconazole resistant candide $\neg$ mia. Antimicrob Agents Chemother 2010; 54:3149-3154.

31. Somer A. Pediatrik hastalarda antifungal tedavi strateji-leri. Ankem Derg 2012; 26: 298-304.

32. Özkaya E, Çalışkan A, Kirişçi Ö ve ark. Son üçyılda Kahramanmaraş Necip Fazıl Şehir Hastanesinde kan kültürlerinden izole edilen Candida türlerinin dağılımı ve antifungal duyarlılıkları. Türk Mikrobiyol Cem Derg 2016; 46: 63-68.

33. Togay A, Bayraktar B, Sevgi DY ve ark. Yatan hastalardan izole edilen Candida türlerinin ve antifungal duyarlılıklarının belirlenmesi. Şişli Etfal Hastanesi Tıp Bülteni 2015; 49: 266-73.

34. YüksekkayaŞ,FındıkD,Arslan U.Yoğun bakımünitesindeyatan hastaların idrarlarından izole edilen Candida türlerinin moleküler epidemiyolojisi ve antifungal duyarlılıkları. Mikrobiyol Bul 2011;45(1): 137-49.

35. Özbek E, Tekay F, Pirinççioğlu HÇ. Yoğun bakım hastalarına ait çeşitli örneklerden izole edilen Candiᄀda izolatlarında antifungal direnç. Dicle Tıp Dergisi 2012; 39: 207-212.

36. Hancı SY, Derici YK, Şirin ML ve ark. Üçüncü basamak bir hastanede, geriatrik olgularda izole edilen Candida türlerinin tiplendirilmesi ve kanda üreyen mayalarda antifungal duyarlılık. Dicle Tıp Derg 2015; 42: 438-444.

37. Murray PR. Rosethal KS. Pfaller MC. Tıbbi Mikrobiyoloji. Başustaoğlu AC ve ark. (Çeviren), 6.Baskı. Ankara: Atlas 2010; 70: 707.

38. Pfaller MA, Castanheira M, Messer SA, Moet GJ, Jones RN. Echinocandin and triazole antifungal susceptibility profiles for Candida spp., Cryptococcus neoformans, and Aspergillus fumi-gatus: application of new CLSI clinical breakpo-ints and epidemiologic cutoff values to characteri-ze resistance in the SENTRY Antimicrobial Surveillance Program (2009), Diagn Microbiol Infect Dis 2011; 69: 45-50.

39. Messer SA, Jones RN, Moet GJ, Kirby JT, Castanheira M. Potency of anidulafungin compared to nine other antifungal agents tested against Candida spp., Cryptococcus spp., and Aspergillus spp. results from the global SENTRY Antimicrobial Surveillance Program (2008) J Clin Microbiol 2010; 48: 2984-7. 